\title{
Influenza a virus-triggered autophagy decreases the pluripotency of human- induced pluripotent stem cells
}

\author{
Ali Zahedi-Amiri ${ }^{1,2}$, Glen L. Sequiera ${ }^{3,4}$, Sanjiv Dhingra ${ }^{3,4}$ and Kevin M. Coombs ${ }^{1,2,5}$
}

\begin{abstract}
Maternal influenza infection during pregnancy was reported multiple times as the possible cause of many defects and congenital anomalies. Apart from several cases of influenza-related miscarriage during various trimesters of pregnancy, some epidemiological data suggest a link between maternal influenza infection and genetic abnormalities in offspring. However, there are no reports yet describing how maternal influenza alters cellular pathways at early stages of development to result in congenital defects in the fetus. In the present study, using proteomic approaches, we utilized human-induced pluripotent stem cells (hiPSCs) for modeling intrablastocyst infection with influenza virus to not only investigate the vulnerability and responses of pluripotent stem cells to this virus but also to determine the possible impacts of influenza on pluripotency and signaling pathways controlling differentiation and embryogenesis. Our data indicated viral protein production in influenza A virus (IAV)-infected hiPSCs. However, viral replication was restricted in these cells, but cell viability and pluripotency were negatively affected. These events occurred simultaneously with an excessive level of IAV-induced autophagy as well as cytopathic effects. Quantitative SOMAscan screening also indicated that changes in the proteome of hiPSCs corresponded to abnormal differentiation in these cells. Taken together, our results showed that IAV-modulated reduction in hiPSC pluripotency is associated with significant activation of autophagy. Further investigations are required to explore the role of IAV-induced autophagy in leading pluripotent stem cells toward abnormal differentiation and impaired development in early stages of embryogenesis.
\end{abstract}

\section{Introduction}

Some influenza pandemics and seasonal epidemics have shown high rates of fatalities in pregnant women and the fetus, suggesting that pregnancy puts both mother and offspring at higher risk of developing flu complications ${ }^{1}$. In addition to influenza-induced miscarriages, maternal influenza infection was reported several times as possible cause of some developmental malformations, but the molecular mechanisms behind such teratogenic effects have remained elusive ${ }^{2-6}$. A few pathologic analyses have

Correspondence: Kevin M. Coombs (kevin.coombs@umanitoba.ca)

'Department of Medical Microbiology and Infectious Diseases, University of Manitoba, Winnipeg, MB, Canada

${ }^{2}$ Manitoba Centre for Proteomics and Systems Biology, Winnipeg, MB, Canada Full list of author information is available at the end of the article.

Edited by G.M. Fimia not only confirmed viremia and extrapulmonary spread of influenza in pregnant women but also its transmission to fetal tissues ${ }^{7-10}$. Influenza-modulated congenital defects are mostly believed to originate from early pregnancy when the unevolved and vulnerable placenta still develops. Although transplacental passage of this virus is debated, embryonic cells can be affected through fetomaternal viral interference in signaling pathways controlling embryogenesis. Influenza replicates in certain multipotent stem cells ${ }^{11-13}$. Nevertheless, Influenza A virus (IAV) has limited replication in mouse embryonic stem cells (mESCs), but reduces their viability even at low multiplicity of infection (MOI), indicating the vulnerability of the blastocyst's inner cell mass (ICM) to IAV ${ }^{14}$. ESCs are pluripotent and present only transiently at the ICM before initiating embryogenesis. Pluripotency is an

\section{(c) The Author(s) 2019}

(c) (i) Open Access This article is licensed under a Creative Commons Attribution 4.0 International License, which permits use, sharing, adaptation, distribution and reproduction cc) in any medium or format, as long as you give appropriate credit to the original author(s) and the source, provide a link to the Creative Commons license, and indicate if changes were made. The images or other third party material in this article are included in the article's Creative Commons license, unless indicated otherwise in a credit line to the material. If material is not included in the article's Creative Commons license and your intended use is not permitted by statutory regulation or exceeds the permitted use, you will need to obtain permission directly from the copyright holder. To view a copy of this license, visit http://creativecommons.org/licenses/by/4.0/. 
essential attribute of pluripotent stem cells (PSCs) and represents the stemness, differentiation capacity, and selfrenewal ability of such cells. Interactions of influenza proteins with themselves and with host cell proteins elicit substantial changes in the proteome to expand viral replication, as noticed by several virus-induced impairments in host cellular machinery affecting apoptosis and autophagy, immune responses, and protein synthesis ${ }^{15-21}$. None of these influenza-mediated alterations have been studied under the pluripotent state on a proteomic scale. Cell death and survival signaling pathways in these, especially after viral infections, are also poorly understood $^{22}$. Additionally, modifications in pluripotency, selfrenewal, and differentiation, as the most critical characteristics of PSCs, have not yet been elucidated under infections with most viruses, including influenza. Humaninduced pluripotent stem cells (hiPSCs), which are generated through reprograming somatic cells, show great promise as both ethical and functional alternatives to ESCs for in vitro modeling of intrablastocyst infections. In the present study, we investigated the effects of IAV on the pluripotency and the proteome of hiPSCs.

\section{Results}

\section{Influenza A/PR/8/34 replicates restrictively in hiPSCs}

Unlike MDCK and A549 epithelial cells, which are permissive to influenza, IAV growth was restricted in hiPSCs at MOIs of 0.1 and 1.0 (Fig. 1a, upper and middle panels). At $24 \mathrm{hpi}$, the maximum titer of $10^{6} \mathrm{PFU} / \mathrm{mL}$ was attained at MOI of 5.0, which appeared to be upward and a little lower than the initial titer at 0 hpi (Fig. 1a, bottom panel). Despite no detectable protein expression at lower MOIs, viral matrix 1 protein (M1), nucleoprotein (NP), and nonstructural-1 protein (NS1) were produced in hiPSCs by 12 hpi at MOI of 5 (Fig. 1b). We further validated the expression of viral proteins and also noticed that an MOI of 5 was adequate to establish infection in nearly $80 \%$ of cells by 24 hpi (Fig. 1c). Although the assembly and maturation of infectious progeny viruses appeared to be limited, these data collectively indicate that influenza $\mathrm{A} / \mathrm{PR} / 8 / 34$ enters the nucleus of hiPSC at higher MOIs and can initiate transcription and replication.

\section{Influenza causes cytopathology and activates autophagy in hiPSCs}

By increasing the MOI, infected cells displayed more cytopathic effects (CPEs), such as shrinkage, rounding, detaching from the culture vessels, and notable reduction in the number and size of colonies, suggesting the induction of cell death (Fig. 2a, b). The viability of PR8infected cells also was reduced (Fig. 2c). These observations confirm cytopathogenic entry of virus. Compared to
A549 cells, IAV did not elevate the cleavage of caspases in hiPSCs by 24 hpi and showed unique cell-specific differences in the expression of apoptosis regulators like Bax, Bcl-2, and p53 (Fig. 2d, left and middle panels), highlighting constrained intrinsic apoptosis in hiPSCs after IAV infection. However, the induction of autophagy after influenza infection was demonstrated by detection of LC3 $\beta$-II, Atg5, and p62 (Fig. 2d, right panel). Taken together, unlike limited intrinsic apoptosis, IAV activated autophagy in hiPSCs earlier than apoptosis executioners and to much higher levels.

\section{IAV infection diminishes pluripotency of hiPSCs}

Although most infected cells showed pluripotency characteristics by 12 hpi (data not shown), an overall decrease of at least $20 \%$ was observed in the expression of pluripotency regulating proteins Nanog, Sox2, and Oct$4 \mathrm{~A}$ after $24 \mathrm{~h}$ at MOI of 5.0 (Fig. 3d). The validation of these results showed similar or greater reduction in levels of pluripotency indicators at $24 \mathrm{hpi}$ (Fig. 3e). IAV NS1 was almost equal between cells producing less Sox2 (Fig. 3b) or Oct-4A (Fig. 3c) and cells with a considerable level of these two proteins. However, apart from edges of infected colonies, NS1 appeared to be more abundant in cells expressing diminished levels of Nanog (Fig. 3a), showing that PR8 virus decreases the pluripotency for expanding its infectivity in hiPSCs.

\section{Inhibition of autophagy maintains pluripotency and limits viral growth}

We found that more than $75 \%$ of hiPSCs remained viable after exposure to $50 \mathrm{nM}$ Rapamycin, an autophagy promoter, for $24 \mathrm{~h}$ (Fig. 4a), while Bafilomycin, which inhibits autophagic activity, was more toxic for these cells, as their treatment with the same concentration resulted in a $50 \%$ drop in cell viability (Fig. 4b). Infection followed by treatment with $50 \mathrm{nM}$ Rapamycin and $5 \mathrm{nM}$ Bafilomycin decreased the viability to below $40 \%$ within $24 \mathrm{~h}$, which is slightly less than the effect of infection alone in the absence of these drugs (Fig. 4c, d, left panels). Although the viral titer at $24 \mathrm{~h}$ after treatment with autophagy inducer did not pass its initial titer at time-point zero, viral yield was increased $\sim$ tenfold by Rapamycin (Fig. 4c, right panel) but, conversely, was decreased tenfold in Bafilomycin-treated cells (Fig. 4d, right panel), suggesting that selected concentrations affect IAV replication in hiPSCs. The conversion of LC3 $\beta$-I to LC3 $\beta$-II, and the degradation of $\mathrm{P} 62$, were significantly upregulated in Rapamycin-treated cells in both infected and noninfected conditions, compared to mock or nontreated controls, whereas autophagy indicators in Bafilomycin-treated cells, either infected or noninfected, were expressed almost similar to mock and nontreated control (Fig. 4e), which 


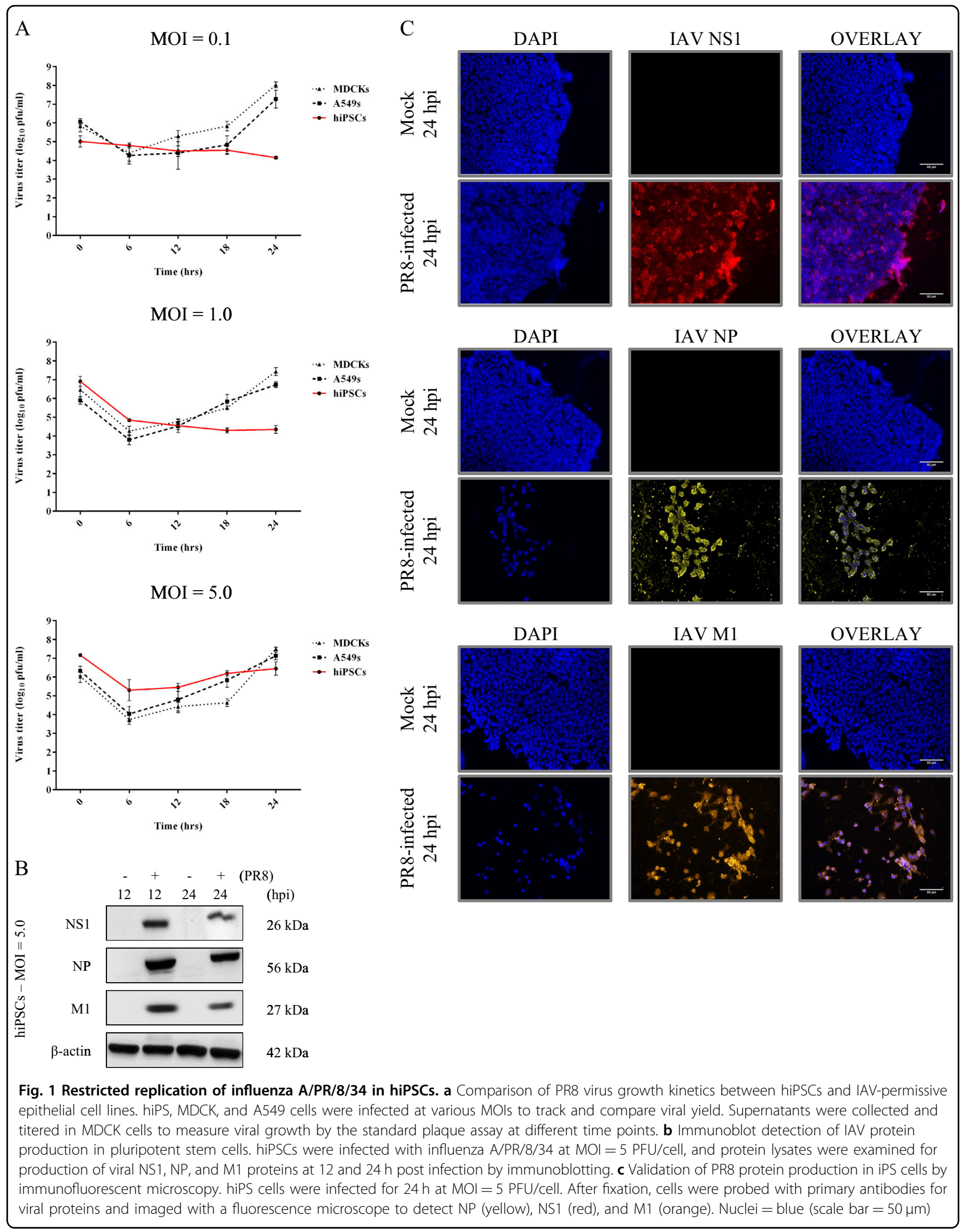




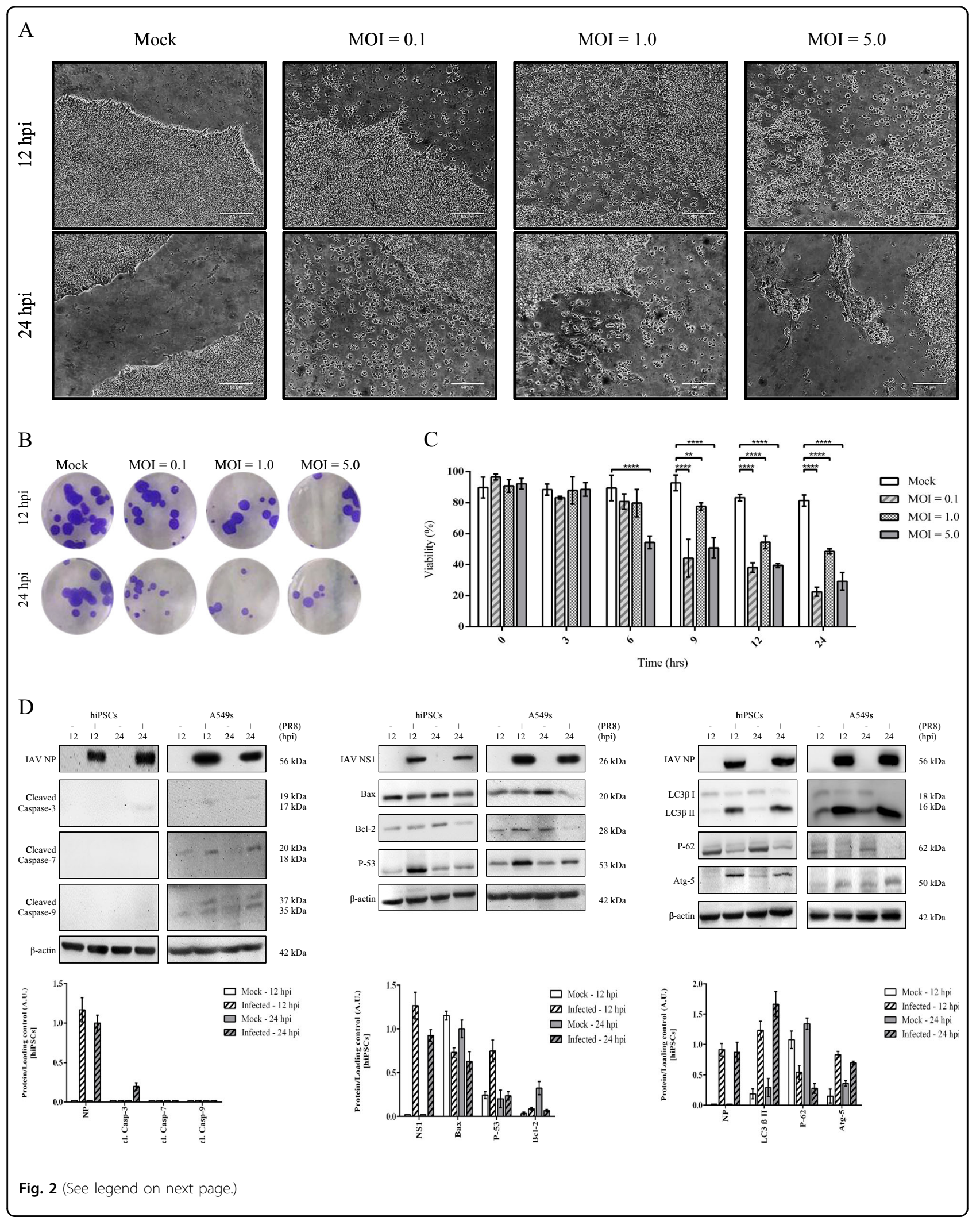


(see figure on previous page)

Fig. 2 Influenza causes cytopathology and activates autophagy in hiPSCs. a Visual examination of IAV-induced CPE in pluripotent stem cells. Mock and virus-infected cells at different MOls were observed under an inverted microscope and photographed at 12 and $24 \mathrm{hpi}(\mathrm{scale}$ bar= $50 \mu \mathrm{m}$ ). b Impact of IAV on the size and numbers of hiPSC colonies. hiPSC colonies were infected with PR8 at three MOls for 12 and $24 \mathrm{~h}$, then fixed with $4 \%$ paraformaldehyde, and stained with crystal violet. Mock-infected colonies of hiPSCs showed deeper staining than infected colonies due to higher cell density per colony. c Quantification of Trypan blue exclusion test of cell viability at different MOls and postinfection time points. In contrast to mockinfected cells, which remained more than $80 \%$ viable for a day, the viability of PR8-infected cells reduced significantly at 24 hpi for all MOls compared to the mock 0 time and time-matched mock controls ( $P$-value $\leq 0.01={ }^{*}, P$-value $\left.\leq 0.0001={ }^{* * *}\right)$. $\mathbf{d}$ Effect of IAV infection on intrinsic apoptosis and autophagy activation. Following infection with PR8 virus at MOI of 5, cell lysates were extracted at 12 and 24 hpi, then fractionated by SDS-PAGE and assessed by western blotting. IAV proteins NP, M1, and NS1 were used as markers of infection. Left panel: compared to A549 cells, PR8 infection did not elevate the cleavage of caspases-7, -3, -9, the main executioners of the intrinsic apoptotic pathway, in hiPSCs by 24 hpi. Middle panel: in contrast to PR8-infected A549 cells which showed clear decrease in the expression of Bax (proapoptotic) at $24 \mathrm{hpi}$, hiPSCs expressed relatively unchanged levels of this protein within $24 \mathrm{~h}$ of infection with influenza, despite the slight reduction in infected cells. The abundance of Bcl-2 (antiapoptotic) was severely decreased one day after infection in both hiPS and A549 cells. Infecting these pluripotent stem cells with PR8 virus resulted in transient p53 accumulation only at $12 \mathrm{hpi}$ without subsequent production at the later time points. Right panel: similar to A549s, IAVinduced autophagy was detected based on LC3 $3-$ I to II conversion, Atg5 accumulation, and p62 degradation

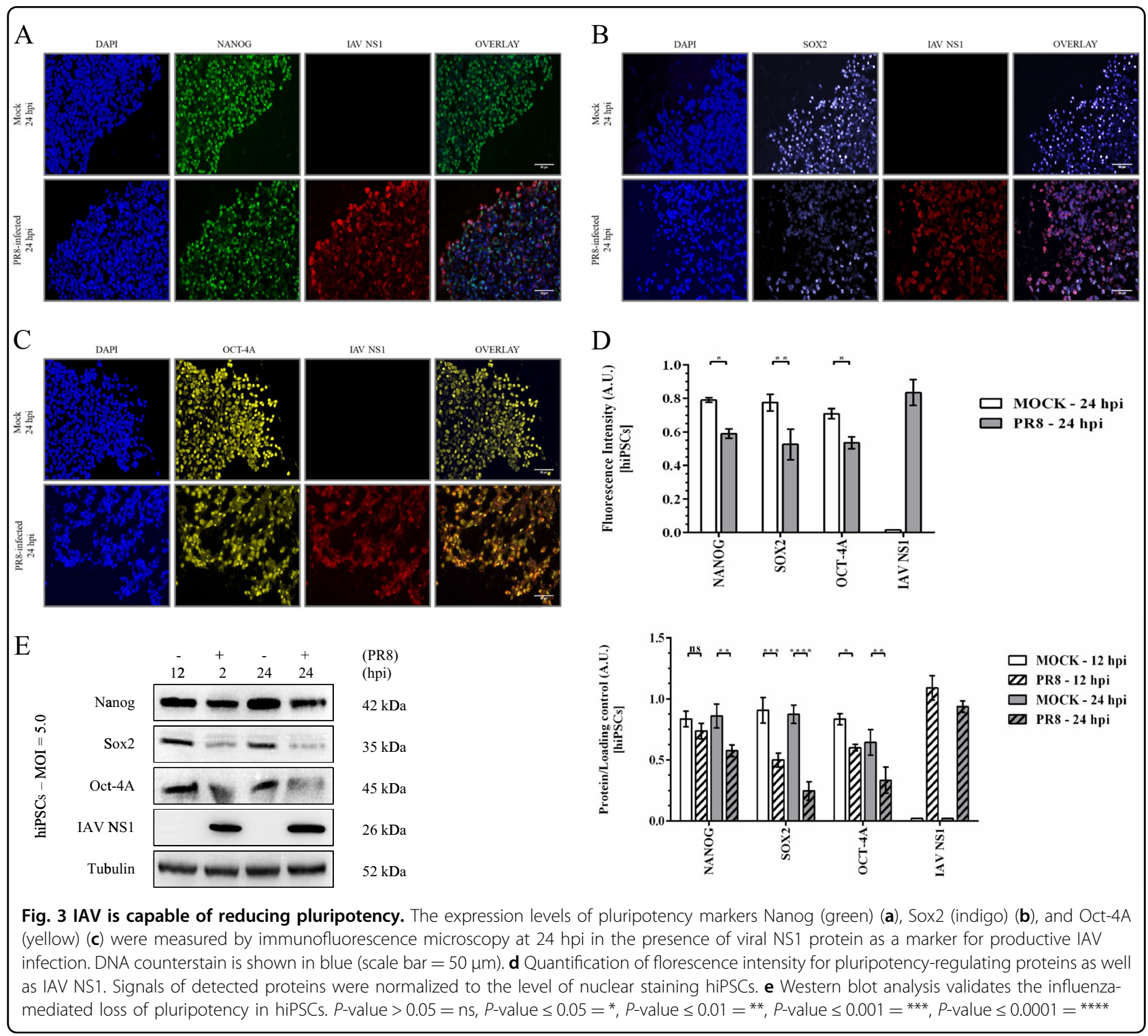




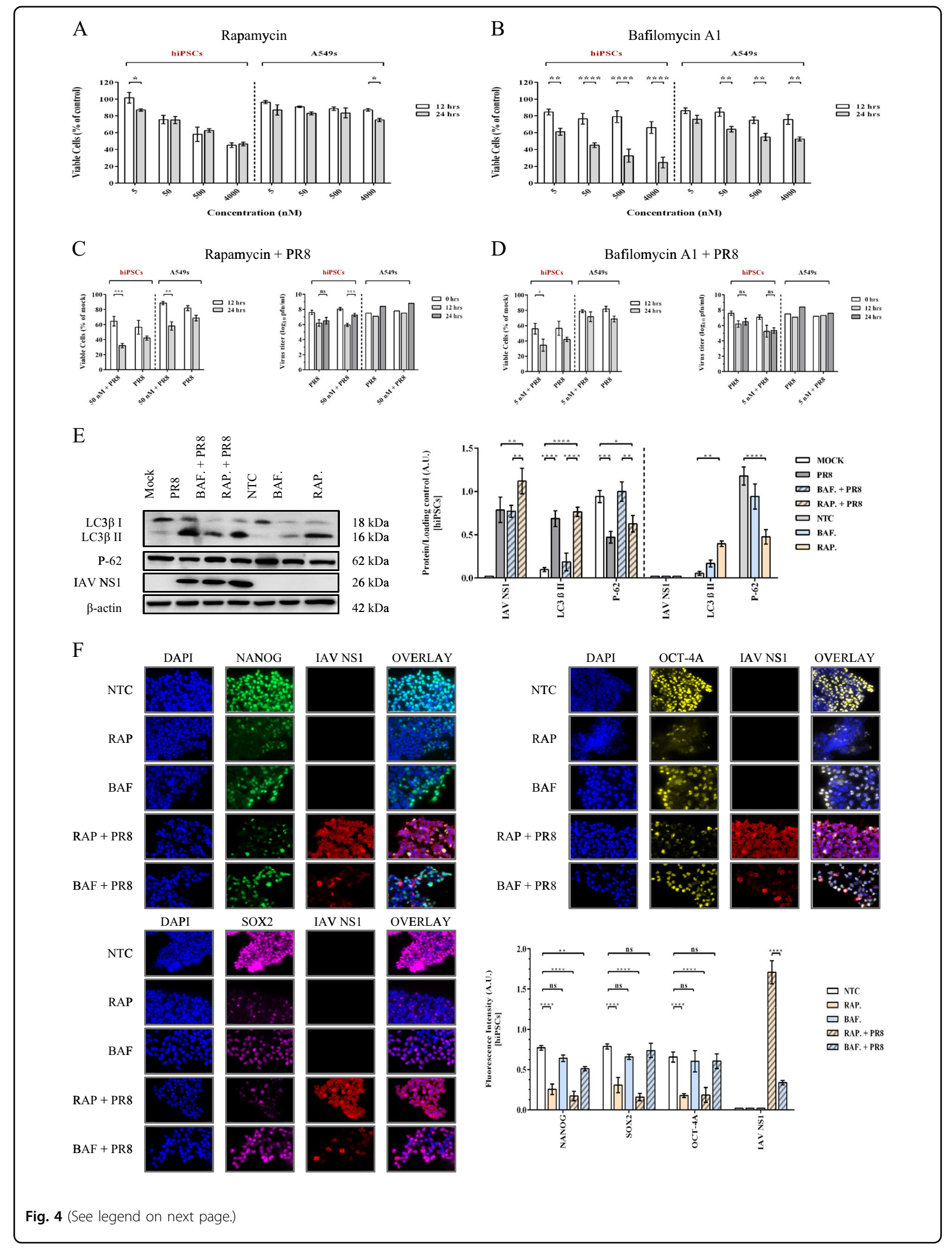


(see figure on previous page)

Fig. 4 Effects of autophagy inhibition and induction on pluripotency and viral growth. Cytotoxicity of Rapamycin (a) and Bafilomycin A1 (b) in hiPSCs and A549s. After treating cells with various concentrations of these drugs, cell viability was assessed by the WST-1 cell proliferation assay at 12 and $24 \mathrm{~h}$. c Rapamycin increases the influenza titer (right panel), despite reducing cell viability in presence of PR8 virus (left panel). d Significant decline of viral titer in infected Bafilomycin-treated cells (right panel) is also associated with reduced cell viability (left panel). Assessment of viral titer was done by the plaque assay. e Expression levels of autophagy markers after exposure to autophagy inducer and inhibitor in infected and noninfected hiPSCs. After treating with drugs, cell lysates were assayed by immunoblotting for detection of LC3 $\beta-I$ to II conversion and p62 degradation. $\mathbf{f}$ Induction of autophagy negatively affects pluripotency, while the inhibition of autophagic activity maintains this characteristic of pluripotent stem cells. The expression of pluripotency proteins Nanog (green), Sox2 (violet), and Oct-4A (yellow) was determined at 24 hpi through immunocytochemistry in presence of viral NS1 protein as a marker for infection. DNA counterstain is shown in blue. $P$-value $\leq 0.05={ }^{*}, P$-value $\leq 0.01$ $={ }^{* *}, P$-value $\leq 0.001=^{* * *}, P$-value $\leq 0.0001=^{* * *}$. Scale bar $=20 \mu \mathrm{m}$

confirms the efficacy of selected concentrations in altering viral-induced autophagy in hiPSCs. Both infected and noninfected Rapamycin-treated cells showed $60 \%$ or more loss in the expression of pluripotency markers, which is more substantial than the effect of infection without Rapamycin (Figs. 3 and 4f). In Bafilomycin-treated cells, pluripotency proteins did not change significantly, but infection with PR8 virus caused slight reduction in their expressions, which were still between twofold and fourfold greater than signals for Rapamycin-treated cells, showing that Bafilomycin reduces the negative effect of influenza-mediated autophagy on pluripotency. Moreover, although our western blotting indicated that Bafilomycin-treated cells can express IAV NS1 protein almost equal to infected nontreated cells, we found that florescence signals for NS1 production were severely decreased and clustered under the influence of Bafilomycin, while the NS1 expression was highly increased by Rapamycin in different assays, compared to normal nontreated infected cells (Figs. 3 and 4e, f). Since both pharmacological promotion of autophagy by Rapamycin and influenza upregulate autophagic activity by inhibiting mechanistic target of rapamycin (mTOR), these results suggest a relationship between influenza-induced autophagy and loss of pluripotency.

\section{PR8 infection alters the hiPSC proteome}

Our SOMAscan screening detected more significantly differentially expressed proteins at $24 \mathrm{hpi}$ than at $12 \mathrm{hpi}$ (Fig. 5a, Table 1). About $6 \%$ of the measured proteome underwent significant modifications by IAV (Fig. 5b). Most of upregulated and downregulated proteins at $12 \mathrm{hpi}$ followed their significant altered pattern of expression to 24 hpi (Fig. 5c). Validating the differential regulations of some proteins revealed similar expression patterns (Fig. $5 \mathrm{~d})$. Most of the affected proteins at $12 \mathrm{hpi}$ were mapped in extracellular (secretory) (39.3\%) and plasma membrane (30.3\%) regions. These two areas collectively contained $54.7 \%$ of influenza-modulated proteins at $24 \mathrm{hpi}$ (Fig. 5e).

\section{Influenza targets proteins controlling embryogenesis}

Interconnecting networks of proteins were created using Ingenuity Pathways Analysis (IPA) software to determine interactions among dysregulated proteins in influenza-infected hiPSCs (Supplementary Fig. 1). Most of the significantly regulated proteins in the embryonic development network were downregulated by IAV (Fig. 6a). IPA also predicted potential inhibition or activation of other member molecules in this network that were not regulated or not found in our dataset (Fig. 6b). Experimental data and bioinformatic prediction connected this network to bio-functions related to stem cells and embryogenesis (Fig. 6c). These influenza-induced dysregulations in protein-protein interaction networks may negatively affect differentiation and embryogenesis.

\section{PR8 virus dysregulates pathways and bio-functions regulating cell differentiation}

IPA identified IAV-modulated pathways in hiPSCs (Fig. 7a, b), some of which are involved in differentiation and pluripotency. The effects of IAV on the member molecules of these pathways are shown in Supplementary Fig. 2. We also generated networks of molecules altered by the virus that individually or collectively mediate modifications in affected pathways (Fig. 7c, d). IPA also predicted decreases in differentiation, embryogenesis, and cell viability, and increase in cell death by 12 hpi (Fig. 8a), indicating that IAV initially causes cell death and suppressed differentiation. Nevertheless, activation of cellular development at $24 \mathrm{hpi}$ (Fig. $8 \mathrm{~b}$ ) suggests the possibility of differentiation.

\section{Discussion}

Many questions concerning the effect of viruses on the unique characteristics of PSCs, like pluripotency, differentiation, and cell death signals, have remained unanswered. Here, we showed that IAV propagates restrictedly in hiPSCs. Wash et al. observed similar limited IAV replication in $\mathrm{mESCs}^{14}$. In our study, higher MOI did not promote PR8 replication but allowed synthesis of viral proteins, including NS1, which alone confirms the transport of viral ribonucleoproteins (vRNPs) into the nucleus, and initiation of transcription and translation. Compared to another (-)ssRNA viruses such as measles, which replicates more in iPSCs ${ }^{23}$, the assembly of progeny IAV viruses was disrupted in our experiments, even 


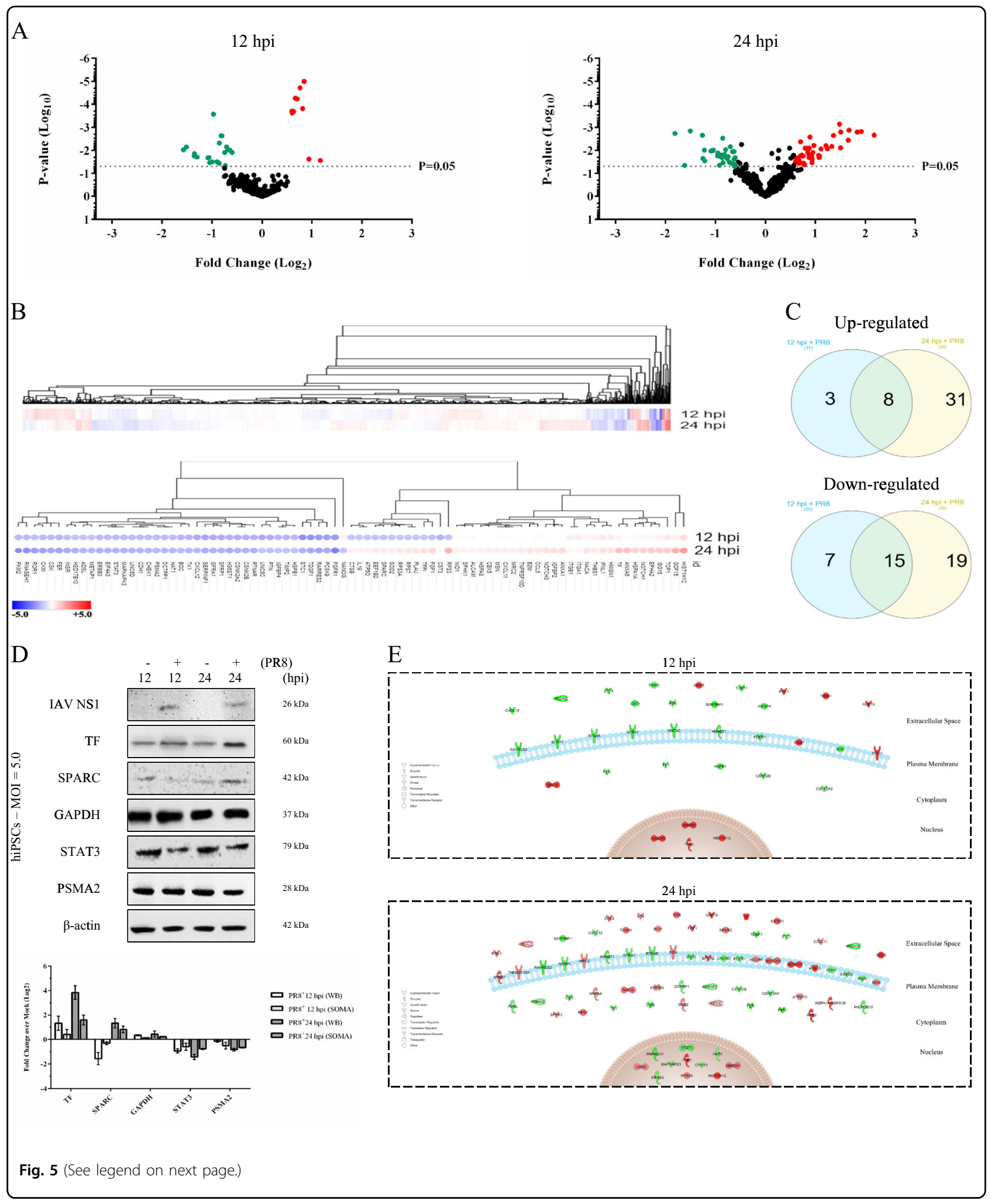

though viral proteins synthesized at higher MOI confirm the cell's transcription machinery is hijacked by IAV. It has been speculated that underdeveloped glycosylation in
PSCs hinders viral haemagglutinin (HA) and neuraminidase (NA) maturation ${ }^{14,24-27}$, thereby resulting in not only reduced binding to cell receptors and less fusion 
(see figure on previous page)

Fig. 5 SOMAscan proteomic analysis of IAV-infected hiPSCs. a Volcano plots showing the expression fold changes and the significance of differentially expressed proteins at 12 and $24 \mathrm{hpi}(P$-value $<0.05)$. b The heatmap of the whole proteome (upper image) and the comparison (lower image) heatmap of differentially expressed proteins. c Venn diagram of the overlapping proteins between two time-points. Diagrams of significantly regulated proteins were plotted using InteractiVenn free online software. $\mathbf{d}$ Western blot confirmation of selected differentially regulated proteins from SOMAscan results. Western blot results are represented from multiple different gels. Various loading control band intensities were used from different gels to perform densitometry normalization and analysis. For validation, proteins were selected based on fold changes, availability of antibodies, and involvement in pluripotency and differentiation. These proteins include serotransferrin (TF), osteonectin (SPARC), glyceraldehyde 3-phosphate dehydrogenase (GAPDH), signal transducer and activator of transcription 3 (STAT3), and proteasome subunit alpha type-2 (PSMA2). Influenza NS1 also was probed to confirm successful infection. e The subcellular localizations of regulated proteins at 12 and 24 hpi. Graphical representation of cellular compartments was illustrated using pathway designer plugin in the IPA tool. Up- and downregulated proteins are highlighted in red and green, respectively

with endosomal membrane but also decreased budding of new virions. The rapid proliferation of PSCs might also have negatively influenced the initial MOI and ultimately the ability of IAV to release measurable progeny, as already reported in ESCs infected with other (-)ssRNA viruses like La Crosse virus (LACV) and Sendai virus ${ }^{28}$. Growth conditions of these cells can also make barriers in simulating a normal in vivo infection. For instance, since iPSCs are grown in colonies on Matrigel-coated surfaces and cannot make confluent monolayers, viruses, as charged particles, might be limited in movement toward colonies because of being partially trapped in Matrigel $^{23,29}$, suggesting efficacy of higher MOIs for sufficient attachment and entry.

We observed that PR8-infected hiPSCs develop CPE. This phenomenon was consistent with low cell viability. Similar CPE and loss in cell viability were reported in IAV-infected $\mathrm{mESCs}^{14}$. Some (-)ssRNA viruses like Measles with efficient replication and LACV with low viral yield, can also develop diverse types of CPE in hiPSCs and mESCs, respectively ${ }^{23,28,30}$. Our observation may suggest that if IAV infection occurs at the blastocyst stage, embryogenesis could be disrupted in cases of transplacental passage as the ICM is directly affected. We also attempted to discover the type of cell death that was elicited by IAV in hiPSCs with primary emphasis on apoptosis, the most common type of programmed cell death that can be induced by IAV through intrinsic and extrinsic mechanisms ${ }^{31,32}$. We showed that PR8 virus does not contribute to intrinsic apoptosis in hiPSCs, as noted by inactivation of caspases, but induces this type of cell death in lung epithelial A549 cells based on differential expression of caspases and apoptosis regulators. Such a cell-specific difference confirms unique expression profiles of intrinsic apoptosis executioners and regulators in hiPSCs. In somatic cells, apoptosis can be temporarily blocked by IAV NS1 protein at preliminary stages of infection via PI3k-Akt signaling pathway for expanding viral replication ${ }^{33-35}$. This early inhibition of apoptosis then is accompanied by apoptotic or necrotic pathways at subsequent phases of infection to promote cell death in infected cells and viral budding ${ }^{36}$. In our study, intrinsic apoptotic response might become activated later (e.g., after $24 \mathrm{hpi}$ ), which we did not investigate here because of decreased cell viability. IAV-induced cell death in hiPSCs might also have occurred via caspase-independent mechanisms (e.g., by extrinsic apoptosis or alternative cell death pathways).

The acidification of endosome-lysosome system is needed for proper function of lysosomal enzyme and fusion of autophagosome with lysosome to complete autophagy, the pathway controlling degradation of dysfunctional organelles and recycling of cellular components ${ }^{37}$. This also provides an optimal condition for uncoating IAV particles and release of $\operatorname{RNPs}^{36,38,39}$. Interestingly, IAV induces autophagy in a variety of mammalian cells by inhibiting mTOR ${ }^{17,40,41}$. Considering the possibility of cell death with autophagy ${ }^{42}$, we detected activation of autophagy in both influenza-infected A549s and hiPSCs. To our knowledge, this is the first evidence of virus-induced autophagy in PSCs, despite the lack of proof to directly link this activated mechanism to demonstrated cell death. After fertilization, autophagy levels were immediately upregulated in murine oocytes ${ }^{43}$. Subsequently, autophagy is inhibited between the oneand two-cell stage but can be increased again at the fourcell stage $e^{44}$. However, this mechanism is not clearly understood under pluripotent state and seemed to be stable and dispensable in ESCs. Consequences of suppressed autophagy in PSCs can be evolved during embryogenesis or later in differentiated cells and include neuronal inclusions, reduced adipose mass, unwanted accumulation of damaged organelles, and defective embryoid body formation in culture with insufficient ATP production $^{45,46}$. In contrast, implications of excessive abnormally induced autophagy may manifest subtlety in undifferentiated PSCs or in derived tissues and yet remain to be determined. The ubiquitin-proteasome system (UPS) may compensate for intrinsically low levels of autophagy in pluripotent state, due to high proteasome 
Table 1 hiPSC proteins affected by PR8 infection

\begin{tabular}{|c|c|c|c|c|c|}
\hline \multirow[b]{2}{*}{ Entrez gene symbol } & \multirow[b]{2}{*}{ Protein name } & \multicolumn{2}{|l|}{$12 \mathrm{hpi}$} & \multicolumn{2}{|l|}{24 hpi } \\
\hline & & Fold change & $P$-value & Fold change & $P$-value \\
\hline HIST1H1C & Histone cluster $1 \mathrm{H} 1$ family member $\mathrm{c}$ & 2.25 & $2.72 \mathrm{E}-02$ & 4.52 & $2.16 \mathrm{E}-03$ \\
\hline TOP1 & DNA topoisomerase I & 1.92 & $2.37 \mathrm{E}-02$ & 2.83 & $7.57 \mathrm{E}-03$ \\
\hline HMGN1 & High mobility group nucleosome binding domain 1 & 1.80 & $1.00 \mathrm{E}-05$ & 1.96 & $6.10 E-03$ \\
\hline IFNL1 & Interferon lambda 1 & 1.76 & $1.51 \mathrm{E}-04$ & 2.08 & $1.64 \mathrm{E}-02$ \\
\hline ITGA1 & Integrin subunit alpha 1 & 1.70 & $1.90 \mathrm{E}-05$ & 1.47 & $5.45 \mathrm{E}-02$ \\
\hline ITGB1 & Integrin subunit beta 1 & 1.70 & $1.90 \mathrm{E}-05$ & 1.47 & $5.45 \mathrm{E}-02$ \\
\hline GDF15 & Growth differentiation factor 15 & 1.64 & $5.70 \mathrm{E}-05$ & 3.78 & $1.51 \mathrm{E}-03$ \\
\hline THBS1 & Thrombospondin 1 & 1.59 & $5.40 \mathrm{E}-05$ & 1.84 & $8.02 E-03$ \\
\hline NANOG & Nanog homeobox & 1.55 & 2.03E-04 & -1.06 & $6.03 \mathrm{E}-01$ \\
\hline NACA & Nascent polypeptide-associated complex alpha subunit & 1.52 & $2.34 \mathrm{E}-04$ & 1.90 & $1.83 \mathrm{E}-02$ \\
\hline ISG15 & ISG15 ubiquitin-like modifier & 1.52 & 1.97E-04 & 2.84 & $1.58 \mathrm{E}-03$ \\
\hline HSPB1 & Heat shock protein family B (small) member 1 & -1.51 & $1.20 \mathrm{E}-02$ & -1.10 & $4.54 \mathrm{E}-01$ \\
\hline TIMP2 & TIMP metallopeptidase inhibitor 2 & -1.56 & $9.90 E-03$ & -1.10 & $3.49 E-01$ \\
\hline $\mathrm{BOC}$ & BOC cell adhesion associated, oncogene regulated & -1.61 & $9.02 \mathrm{E}-03$ & -1.42 & $1.18 \mathrm{E}-01$ \\
\hline IGFBP4 & Insulin like growth factor binding protein 4 & -1.63 & $6.99 E-03$ & -1.14 & $2.80 \mathrm{E}-01$ \\
\hline FER & FER tyrosine kinase & -1.66 & 4.61E-02 & -2.38 & $2.23 \mathrm{E}-02$ \\
\hline TK1 & Thymidine kinase 1 & -1.67 & $1.22 \mathrm{E}-02$ & -1.62 & $1.37 \mathrm{E}-02$ \\
\hline RNASEH1 & Ribonuclease $\mathrm{H} 1$ & -1.68 & $1.00 \mathrm{E}-05$ & -2.83 & $1.42 \mathrm{E}-03$ \\
\hline CST3 & Cystatin C & -1.74 & $2.29 \mathrm{E}-03$ & 1.20 & $5.34 \mathrm{E}-02$ \\
\hline RTN4R & Reticulon 4 receptor & -1.76 & $2.26 \mathrm{E}-03$ & -1.84 & $1.56 \mathrm{E}-02$ \\
\hline CSNK2B & Casein kinase 2 beta & -1.80 & $4.76 \mathrm{E}-03$ & -1.78 & $1.61 \mathrm{E}-02$ \\
\hline CSNK2A2 & Casein kinase 2 alpha 2 & -1.80 & 4.76E-03 & -1.78 & $1.61 \mathrm{E}-02$ \\
\hline HS6ST1 & Heparan sulfate 6-O-sulfotransferase 1 & -1.81 & $3.62 E-02$ & -1.91 & $1.73 E-02$ \\
\hline PTN & Pleiotrophin & -1.86 & $3.13 \mathrm{E}-02$ & -1.20 & $1.57 \mathrm{E}-01$ \\
\hline SFRP1 & Secreted frizzled related protein 1 & -1.96 & $2.67 \mathrm{E}-04$ & -1.80 & $5.91 \mathrm{E}-03$ \\
\hline UNC5C & UNC-5 netrin receptor $C$ & -1.99 & $3.14 \mathrm{E}-02$ & -1.15 & $2.83 E-01$ \\
\hline GFRA1 & GDNF family receptor alpha 1 & -2.06 & $3.40 E-02$ & -1.80 & $3.44 E-02$ \\
\hline CXCL12 & C-X-C motif chemokine ligand 12 & -2.08 & $2.03 \mathrm{E}-02$ & -1.54 & $2.21 \mathrm{E}-02$ \\
\hline SERPINF1 & Serpin family F member 1 & -2.11 & $2.08 \mathrm{E}-02$ & -1.94 & $1.68 \mathrm{E}-02$ \\
\hline PCSK9 & Proprotein convertase subtilisin/kexin type 9 & -2.46 & $1.93 \mathrm{E}-02$ & -2.07 & $9.92 \mathrm{E}-03$ \\
\hline RARRES2 & Retinoic acid receptor responder 2 & -2.55 & 1.37E-02 & -2.33 & $9.53 \mathrm{E}-03$ \\
\hline FGFR1 & Fibroblast growth factor receptor 1 & -2.56 & $1.70 E-02$ & -3.50 & $1.81 \mathrm{E}-03$ \\
\hline TDGF1 & Teratocarcinoma-derived growth factor 1 & -2.85 & $6.99 \mathrm{E}-03$ & -2.12 & $1.05 \mathrm{E}-02$ \\
\hline STC1 & Stanniocalcin 1 & -2.97 & $9.27 \mathrm{E}-03$ & -1.89 & 4.41E-02 \\
\hline RPS3 & Ribosomal protein S3 & -1.13 & $5.69 \mathrm{E}-01$ & 3.58 & $1.58 \mathrm{E}-03$ \\
\hline ANXA5 & Annexin A5 & 1.14 & $3.55 \mathrm{E}-01$ & 3.19 & $1.31 \mathrm{E}-03$ \\
\hline TF & Transferrin & 1.39 & $3.40 \mathrm{E}-01$ & 3.16 & $3.58 \mathrm{E}-03$ \\
\hline EPHA2 & $\mathrm{EPH}$ receptor $\mathrm{A} 2$ & 1.39 & $1.40 \mathrm{E}-01$ & 2.80 & $7.14 \mathrm{E}-04$ \\
\hline
\end{tabular}


Table 1 continued

\begin{tabular}{|c|c|c|c|c|c|}
\hline \multirow[b]{2}{*}{ Entrez gene symbol } & \multirow[b]{2}{*}{ Protein name } & \multicolumn{2}{|l|}{$12 \mathrm{hpi}$} & \multicolumn{2}{|l|}{$24 \mathrm{hpi}$} \\
\hline & & Fold change & $P$-value & Fold change & $P$-value \\
\hline NOTCH1 & Notch 1 & 1.42 & $2.29 E-01$ & 2.58 & $2.26 \mathrm{E}-03$ \\
\hline HSPA1A & Heat shock protein family A (Hsp70) member $1 \mathrm{~A}$ & 1.25 & 1.17E-01 & 2.52 & $6.64 \mathrm{E}-03$ \\
\hline FGF1 & Fibroblast growth factor 1 & -1.28 & $3.95 \mathrm{E}-01$ & 2.36 & $8.33 \mathrm{E}-03$ \\
\hline ANXA1 & Annexin A1 & 1.10 & $6.39 E-01$ & 2.32 & $6.23 \mathrm{E}-03$ \\
\hline IGFBP2 & Insulin like growth factor binding protein 2 & 1.00 & $9.94 \mathrm{E}-01$ & 2.17 & $8.64 \mathrm{E}-03$ \\
\hline TFPI & The tissue factor pathway inhibitor & -1.05 & $8.21 \mathrm{E}-01$ & 2.12 & $1.76 \mathrm{E}-02$ \\
\hline $\mathrm{NOTCH} 3$ & Notch 3 & 1.19 & 4.36E-01 & 2.11 & $2.02 \mathrm{E}-02$ \\
\hline CCL5 & $\mathrm{C}-\mathrm{C}$ motif chemokine ligand 5 & 1.24 & 2.87E-01 & 1.94 & $1.23 \mathrm{E}-02$ \\
\hline PLAU & Plasminogen activator, urokinase & -1.00 & $9.80 \mathrm{E}-01$ & 1.91 & $2.46 \mathrm{E}-02$ \\
\hline RPS7 & Ribosomal protein S7 & -1.00 & $9.77 \mathrm{E}-01$ & 1.91 & $3.39 E-02$ \\
\hline B2M & Beta-2-microglobulin & 1.04 & $8.52 \mathrm{E}-01$ & 1.86 & $2.61 \mathrm{E}-03$ \\
\hline TNFRSF10D & TNF receptor superfamily member $10 \mathrm{~d}$ & 1.17 & 1.99E-01 & 1.84 & $2.06 \mathrm{E}-02$ \\
\hline SPARC & Secreted protein acidic and cysteine rich & -1.23 & $2.02 E-01$ & 1.83 & $1.48 \mathrm{E}-02$ \\
\hline RPS3A & Ribosomal protein S3A & -1.03 & $8.53 \mathrm{E}-01$ & 1.81 & $8.07 \mathrm{E}-03$ \\
\hline EEF1B2 & Eukaryotic translation elongation factor 1 beta 2 & -1.10 & $6.86 \mathrm{E}-01$ & 1.80 & 1.19E-02 \\
\hline MRC2 & Mannose receptor $\mathrm{C}$ type 2 & 1.15 & $5.09 \mathrm{E}-01$ & 1.74 & $7.98 \mathrm{E}-03$ \\
\hline CBX5 & Chromobox 5 & 1.08 & $6.93 \mathrm{E}-01$ & 1.73 & 4.16E-02 \\
\hline CXCL11 & C-X-C motif chemokine ligand 11 & 1.11 & $6.10 \mathrm{E}-01$ & 1.70 & $3.60 \mathrm{E}-02$ \\
\hline SOD2 & Superoxide dismutase 2 & -1.08 & $5.51 \mathrm{E}-01$ & 1.69 & $1.74 \mathrm{E}-02$ \\
\hline MSN & Moesin & 1.14 & $5.16 \mathrm{E}-01$ & 1.66 & $1.57 \mathrm{E}-02$ \\
\hline ATP5O & ATP synthase peripheral stalk subunit OSCP & -1.08 & $7.09 E-01$ & 1.63 & $8.31 \mathrm{E}-03$ \\
\hline IL19 & Interleukin 19 & -1.05 & $7.26 \mathrm{E}-01$ & 1.62 & $1.81 \mathrm{E}-02$ \\
\hline ALCAM & Activated leukocyte cell adhesion molecule & 1.29 & $2.87 \mathrm{E}-01$ & 1.60 & $3.65 \mathrm{E}-02$ \\
\hline HSPA8 & Heat shock protein family A (Hsp70) member 8 & 1.07 & $5.76 \mathrm{E}-01$ & 1.60 & $2.78 \mathrm{E}-02$ \\
\hline SPHK1 & Sphingosine kinase 1 & 1.17 & $5.26 \mathrm{E}-01$ & 1.54 & $2.56 \mathrm{E}-02$ \\
\hline NID1 & Nidogen 1 & 1.25 & $3.90 \mathrm{E}-01$ & 1.52 & $3.21 \mathrm{E}-02$ \\
\hline CTSB & Cathepsin B & -1.01 & $9.41 \mathrm{E}-01$ & 1.52 & $2.02 \mathrm{E}-02$ \\
\hline HAT1 & Histone acetyltransferase 1 & -1.45 & $2.25 E-01$ & -1.52 & $4.12 \mathrm{E}-02$ \\
\hline DCTPP1 & dCTP pyrophosphatase 1 & -1.44 & $2.73 E-01$ & -1.52 & $4.11 \mathrm{E}-02$ \\
\hline METAP1 & Methionyl aminopeptidase 1 & -1.12 & $6.67 \mathrm{E}-01$ & -1.53 & 4.97E-02 \\
\hline PSMA2 & Proteasome subunit alpha 2 & -1.43 & 2.07E-01 & -1.55 & $2.39 \mathrm{E}-02$ \\
\hline CHEK1 & Checkpoint kinase 1 & -1.48 & $1.32 \mathrm{E}-01$ & -1.57 & $2.32 \mathrm{E}-02$ \\
\hline $\mathrm{CDH} 1$ & Cadherin 1 & -1.39 & $2.16 \mathrm{E}-01$ & -1.58 & $2.24 \mathrm{E}-02$ \\
\hline ADSL & Adenylosuccinate lyase & -1.19 & $2.60 E-01$ & -1.58 & 3.77E-02 \\
\hline UNC5D & unc-5 netrin receptor $\mathrm{D}$ & -1.45 & $1.23 \mathrm{E}-01$ & -1.64 & $3.28 \mathrm{E}-02$ \\
\hline MAPKAPK3 & Mitogen-activated protein kinase-activated protein kinase 3 & -1.41 & $2.15 E-01$ & -1.68 & $1.84 \mathrm{E}-02$ \\
\hline STAT3 & Signal transducer and activator of transcription 3 & -1.40 & $1.73 \mathrm{E}-01$ & -1.70 & $2.30 \mathrm{E}-02$ \\
\hline EIF4A3 & Eukaryotic translation initiation factor $4 \mathrm{~A} 3$ & -1.39 & 2.23E-01 & -1.74 & $9.16 \mathrm{E}-03$ \\
\hline
\end{tabular}


Table 1 continued

\begin{tabular}{|c|c|c|c|c|c|}
\hline \multirow[b]{2}{*}{ Entrez gene symbol } & \multirow[b]{2}{*}{ Protein name } & \multicolumn{2}{|l|}{$12 \mathrm{hpi}$} & \multicolumn{2}{|l|}{$24 \mathrm{hpi}$} \\
\hline & & Fold change & $P$-value & Fold change & $P$-value \\
\hline ERBB3 & erb-b2 receptor tyrosine kinase 3 & -1.43 & $1.39 \mathrm{E}-01$ & -1.77 & $1.49 \mathrm{E}-02$ \\
\hline HSD17B10 & Hydroxysteroid 17-beta dehydrogenase 10 & -1.11 & $6.21 \mathrm{E}-01$ & -1.82 & $2.06 \mathrm{E}-02$ \\
\hline INSR & Insulin receptor & -1.38 & $2.73 \mathrm{E}-01$ & -1.93 & $1.28 \mathrm{E}-02$ \\
\hline CSK & C-terminal Src kinase & -1.58 & $2.76 \mathrm{E}-01$ & -2.06 & $9.52 \mathrm{E}-03$ \\
\hline CKM & Creatine kinase, M-type & -1.48 & $3.88 \mathrm{E}-01$ & -2.32 & $2.85 \mathrm{E}-02$ \\
\hline ROR1 & Receptor tyrosine kinase like orphan receptor 1 & -1.35 & $2.60 \mathrm{E}-01$ & -2.39 & $2.18 \mathrm{E}-03$ \\
\hline PKM2 & Pyruvate kinase M1/2 & -1.48 & $5.20 \mathrm{E}-01$ & -3.06 & $4.48 \mathrm{E}-02$ \\
\hline
\end{tabular}

activity in these undifferentiated cells. Conversely, polyubiquitinated proteins are highly expressed in differentiated cells, and proteasome activity is progressively inhibited during differentiation process ${ }^{47}$. Furthermore, higher levels of autophagy were naturally observed during the differentiation of ESCs, probably through degrading protein complexes regulating pluripotency ${ }^{48}$. Many viruses develop mechanisms to evade, subvert, or exploit cellular processes for their benefit. We speculate that IAV induces autophagy in hiPSCs differently from its normal upregulation upon certain conditions. Such an altered viral-triggered mechanism under pluripotency state suggests the possibility of abnormal differentiation, as elevated levels of autophagy are usually seen in differentiating PSCs. It is thus necessary to evaluate the pluripotency and capacities of these cells for normal differentiation into germ layers after IAV infection to decipher the role of influenza-induced autophagy in abnormal embryonic specification. Hypothetically, with regards to demonstrated cell death, the virus may simultaneously put iPSCs under differentiation and promote autophagy, or may keep them in an undifferentiated state while increasing autophagic activity. It is also possible that the expected differentiation is not directly modulated by the virus itself and could be the outcome of virus-induced excessive autophagy. In all cases, cell death could be executed via different pathways and whether autophagy is actually playing a role in the cellular demise of iPSCs remains unclear ${ }^{42}$.

The effects of viral replication or entry on pluripotency have not yet been described for most viruses. Moreover, specifying the level of pluripotency indicates the possibility of differentiation in virus-infected iPSCs. We found influenza-infected hiPSCs to exhibit a remarkable decrease in the expression of pluripotency regulating proteins Nanog, Sox2, and Oct-4A. This is the first evidence so far that proves PR8 infection negatively affects the pluripotency of hiPSCs. Measles, as the only other (-)
ssRNA virus tested for its effect on pluripotency, was incapable of altering this intrinsic feature of PSCs, but blocks their directed differentiation to germ layers due to extensive $\mathrm{CPEs}^{23}$. Significant levels of cell death that happened by $24 \mathrm{hpi}$ and necessity of using higher MOI did not allow us to test the capability of PR8-infected cells for further differentiation into germ layers. Nevertheless, reduced pluripotency noted in the current study together with our findings regarding IAV-induced autophagy highlight a link between excessive autophagy and loss of pluripotency. Some studies suggest that mTOR acts as the regulator of pluripotency and self-renewal in hESCs, in addition to its central role in the regulation of the autophagy pathway and triggering several downstream pathways including PI3-kinase/Akt and AMP-activated protein kinase ${ }^{44,49,50}$. Zhou and coworkers reported a set of outcomes in hESCs after inhibition or depletion of mTOR, including considerable reduction in expression of Oct4 and Sox2, elevated mesoderm and endoderm differentiation, and limited proliferation ${ }^{51}$. At $24 \mathrm{hpi}$, we obtained similar results; decreased expression of Oct 4 and Sox2 after influenza-induced autophagy. Additionally, our SOMAscan proteomic screening revealed evidence of potentially abnormal differentiation based on dysregulated proteins at the same postinfection time point. In A549 cells, mTOR inhibition with Rapamycin was reported to upregulate autophagy and production of viral NP and NS1 proteins, but did not increase viral yield ${ }^{36}$. We also pharmacologically inhibited mTOR in hiPSCs using Rapamycin and noticed significant loss of pluripotency, but higher levels of viral growth, viral protein production, and autophagic activity. In our study, PR8infected hiPSCs showed not only evidence of viral protein production but also restricted viral replication and caspase-independent or nonapoptotic cell death under excessive autophagic activity. Irrespective of our previous assumptions about the type of cell death and possible reasons for limited viral replication, it has also been 
A

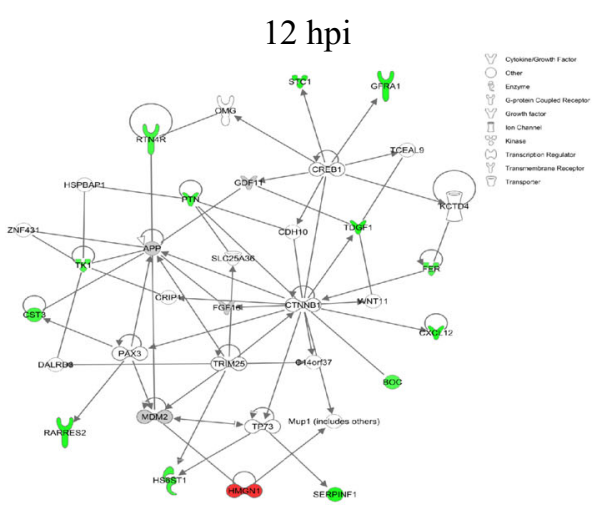

$24 \mathrm{hpi}$

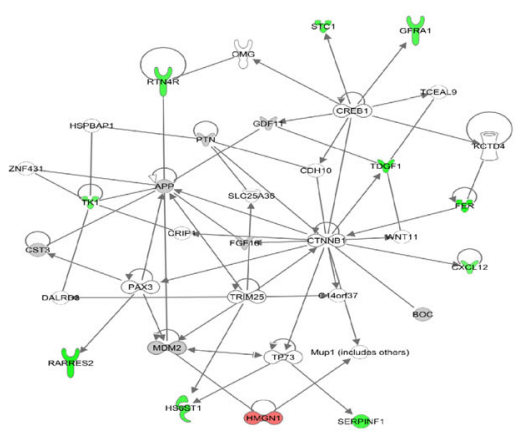

$\mathrm{B}$
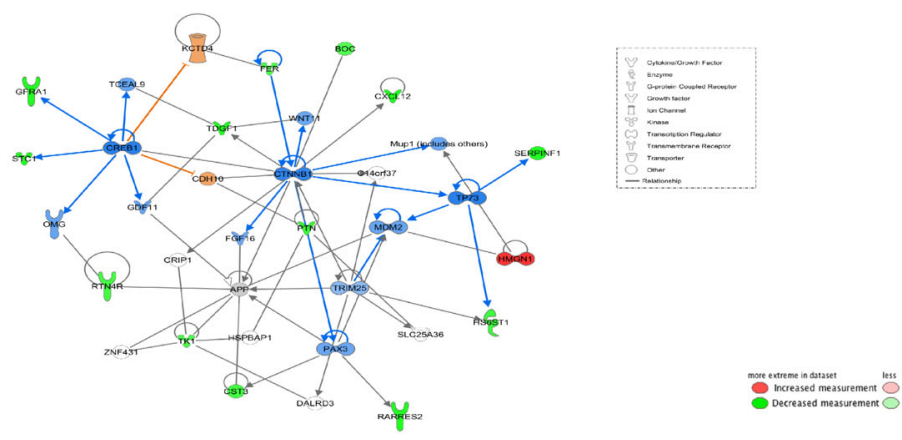

$\mathrm{C}$

\begin{tabular}{cccc} 
Functions & Prediction & p-value & $\begin{array}{c}\text { Molecules } \\
\text { development of body trunk }\end{array}$ \\
Inhibited & $1.08 \mathrm{E}-08$ & $\begin{array}{c}\text { CREB1, CRIP1, CST3, CTNNB1, CXCL12, } \\
\text { FGF16, GDF11, HS6ST1, MDM2, PAX3, PTN, } \\
\text { TDGF1, TK1, TP73, TRIM25, WNT11 }\end{array}$ \\
\hline cardiogenesis & Inhibited & $8.35 \mathrm{E}-08$ & $\begin{array}{c}\text { CREB1, CRIP1, CTNNB1, CXCL12, FGF16, } \\
\text { GDF11, MDM2, PAX3, TDGF1, TP73, WNT11 }\end{array}$ \\
\hline development of body axis & Inhibited & $4.57 \mathrm{E}-07$ & $\begin{array}{c}\text { APP, CREB1, CST3, CTNNB1, CXCL12, } \\
\text { GDF11, HS6ST1, MDM2, RTN4R, SERPINF1, } \\
\text { STC1, TDGF1, TP73, WNT11 }\end{array}$ \\
\hline proliferation of stem cells & Inhibited & $9.42 \mathrm{E}-07$ & $\begin{array}{c}\text { APP, CTNNB1, CXCL12, PAX3, RARRES2, } \\
\text { SERPINF1, WNT11 }\end{array}$ \\
\hline vasculogenesis & Inhibited & $1.22 \mathrm{E}-06$ & $\begin{array}{c}\text { APP, CREB1, CST3, CTNNB1, CXCL12, } \\
\text { HS6ST1, PTN, SERPINF1, STC1, TDGF1, TP73, } \\
\text { WNT11 }\end{array}$ \\
\hline proliferation of embryonic cells & Inhibited & $2.55 \mathrm{E}-06$ & $\begin{array}{c}\text { APP, CTNNB1, CXCL12, PTN, RARRES2, } \\
\text { SERPINF1, WNT11 }\end{array}$ \\
\hline growth of embryonic tissue & Inhibited & $6.12 \mathrm{E}-06$ & $\begin{array}{c}\text { APP, CST3, CTNNB1, CXCL12, PTN, } \\
\text { RARRES2, WNT11 }\end{array}$ \\
\hline differentiation of stem cells & Inhibited & $6.46 \mathrm{E}-05$ & $\begin{array}{c}\text { APP, CTNN1, GFRA1, MDM2, SERPINF1, } \\
\text { WNT11 }\end{array}$
\end{tabular}

Fig. 6 Influenza affects proteins regulating embryonic development network. a Changes in embryonic development network across two timepoints. $\mathbf{b}$ IPA prediction on the expression patterns of molecules that belong to the embryonic development network but not found to be either differentially regulated or identified in our datasets. c Selection of some bio-functions that were predicted to be inhibited based on this network. These functions are mostly related to early differentiation phase of embryonic stem cells and embryogenesis. The datasets containing protein IDs, fold changes, and P-values were imported into the IPA software, and interacting networks were assembled for differentially expressed proteins. Upand downregulated proteins are indicated in red and green, respectively; gray proteins denote that they were identified in this study but not affected; colorless proteins interact with various proteins in the network but were not recognized by our SOMAscan screening. IPA "Grow tool" and bioinformatic predictions were used to connect bio-functions to the network 


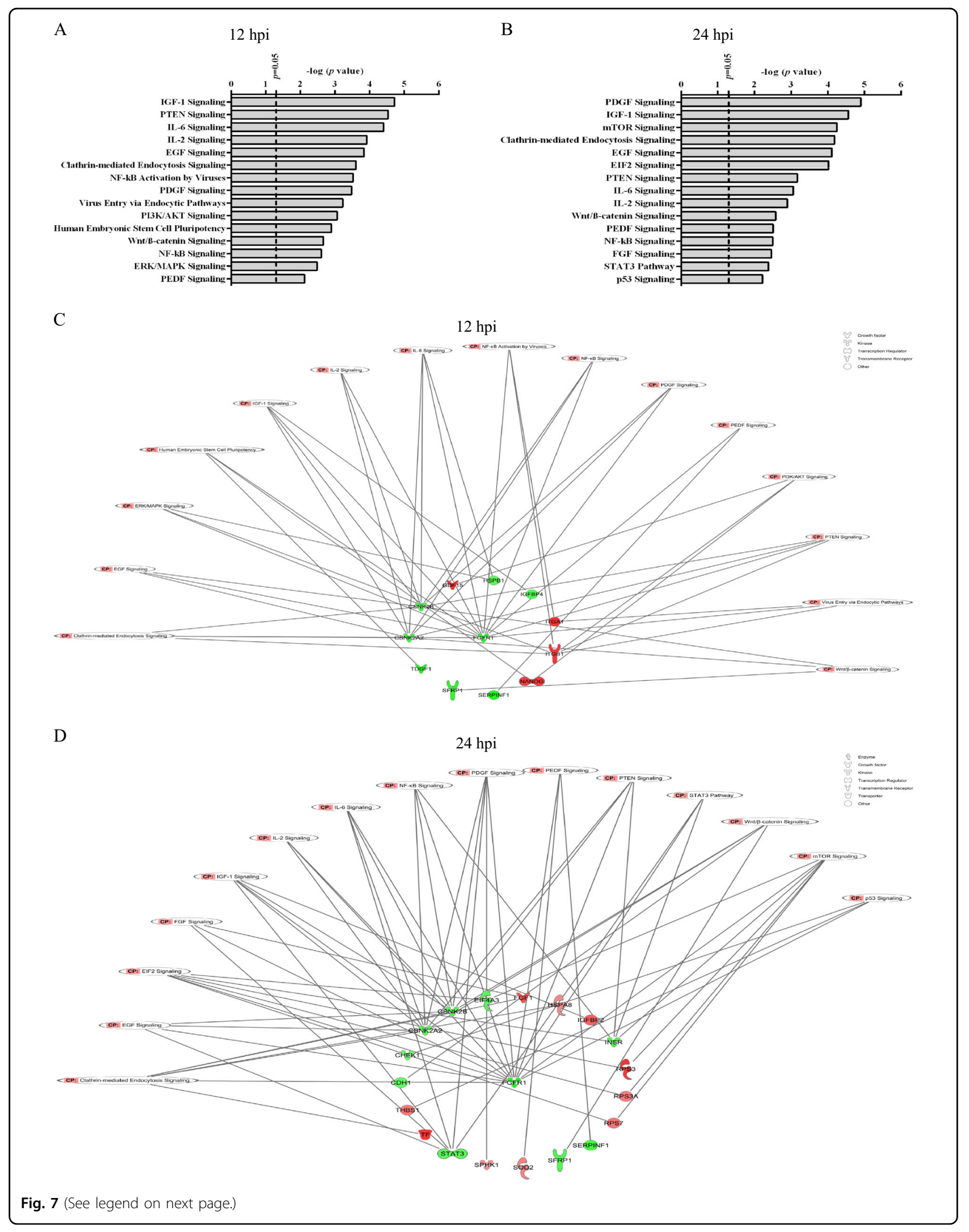


(see figure on previous page)

Fig. 7 Top-affected canonical pathways in hiPSCs after PR8 infection. Protein IDs together with their P-values and levels of regulation were uploaded into IPA tool. In the canonical pathway section, $P$-values of pathways were automatically calculated by the software and top significantly affected pathways were graphed for $12 \mathrm{hpi}$ (a) and $24 \mathrm{hpi}(\mathbf{b})$. Because the affected member molecules from these targeted pathways were fewer than the total numbers of molecules present in those pathways based on SOMAscan screening, IPA software did not predict significant inhibition or activation patterns for the vast majority of influenza-modulated signaling pathways. c, d Network of common molecules mediating influenzainduced alterations into top-affected canonical pathways at 12 and $24 \mathrm{hpi}$. Up- and downregulated proteins are shown in red and green, respectively

hypothesized that mTOR suppression stimulates upstream receptor tyrosine kinase signaling, subsequently activating the Akt/PKB pathway, which may inhibit apoptosis. According to a transcriptomic analysis, mTOR is upregulated during differentiation and afterward compared to its expression under the pluripotent state $^{52}$. We did not directly evaluate the expression of mTOR in IAVinfected hiPSCs. However, our SOMAscan proteomic screen showed that some mTOR-signaling molecules like FGFR1 and INSR1, that are expected to be upregulated upon pathway activation, were downregulated by $24 \mathrm{hpi}$, suggesting potential IAV-triggered inhibition of this pathway. Hence, our results, and those of others, suggest that PR8 virus promotes autophagy in these PSCs, possibly by downregulating mTOR, which decreases pluripotency, ultimately inducing abnormal differentiation. Further investigations are required to explain the initiation of influenza-induced autophagy in PSCs and its possible effect on differentiation.

Our proteomic analyses showed that PR8 virus altered the proteome of hiPSCs. This observation is consistent with what has been previously reported about the limited responses of these cells to most viruses ${ }^{53}$. Likewise, mESCs had also indicated minor dysregulations at the transcriptomic level after $6 \mathrm{~h}$ of infection with influenza ${ }^{14}$. Such limited host responses to influenza infection might be because of inhibited viral replication in these pluripotent cell populations. At $12 \mathrm{hpi}$, although a few proteins like Interleukin-29 (IL-29/IFNL1) and Interferonstimulated gene 15 (ISG15), that are involved in type 3 and 1 interferon responses, were upregulated less than twofold, an apparent deficiency was noticed in the expression of proteins related to innate immune responses against viruses. Inactivated immune responses were already seen in PSCs after different viral or bacterial infections and are mainly due to underdeveloped innate immunity and mutual inhibition between the IFN system and pluripotent state in these cells ${ }^{53-55}$. Highly conserved regulation of transcription in ESCs can be considered another condition that may downregulate interferonstimulated genes for maintaining pluripotency ${ }^{14,56}$. Bioinformatic analyses of differentially regulated proteins at $12 \mathrm{hpi}$ also highlighted significant negative impacts on activation of some canonical pathways controlling immune responses, including leukocyte extravasation signaling, IL-2 signaling, and IL-6 signaling. It is possible that the 1.5-fold upregulation of ISG15 at this time point can be partially explained by the intrinsic immature immunity of PSCs to IAV, as it has been shown that this protein can ISGylate IAV NS1 protein which leads to the inefficiency of NS1 and limited viral replication, the same situation we observed experimentally. IPA software also predicted some potentially affected bio-functions, and these data collectively support the induction of cell death by either necrosis or apoptosis, reduction of cell viability, and inhibition of differentiation in ESCs. We found these bioinformatic predictions reliable and consistent with what we have already acquired on induction of cell death and stable pluripotency at $12 \mathrm{hpi}$. Even though we did not show the normal expression of pluripotency markers by $12 \mathrm{hpi}$ through other assays, our proteomic screening determined the upregulation of Nanog, thus confirming the pluripotency of PR8-infected hiPSCs and repressed differentiation at the mentioned time point. In contrast, at $24 \mathrm{hpi}$, IPA detected unexpected dysregulations among some top-affected canonical pathways that are involved in processing differentiation and embryogenesis. More studies should be carried out to test whether IAV-induced changes could influence the normal differentiation of PSCs into germ layers.

In conclusion, our results indicated IAV causes cytopathology in hiPSCs and can reduce their viability and pluripotency. It was also noticed that such an IAVtriggered decline in pluripotency is associated with an excessive level of autophagy. Moreover, our proteomic screening suggests dysregulations in several cellular pathways and bio-functions regulating differentiation. Further studies are needed to discover the molecular mechanisms involved in initiation of influenza-induced autophagy in PSCs and their possible effects on the signaling pathways controlling embryogenesis.

\section{Materials and methods \\ Cells and viruses}

hiPS cells were generated from human peripheral blood mononuclear cells (PBMCs) using the Sendai virus Kit (Life Technologies), as described previously ${ }^{57}$. All protocols were approved by the Research Ethics Board (REB) of the University of Manitoba. Human influenza virus strain A/PR/8/34 (H1N1; PR8), an attenuated mouse-adapted 


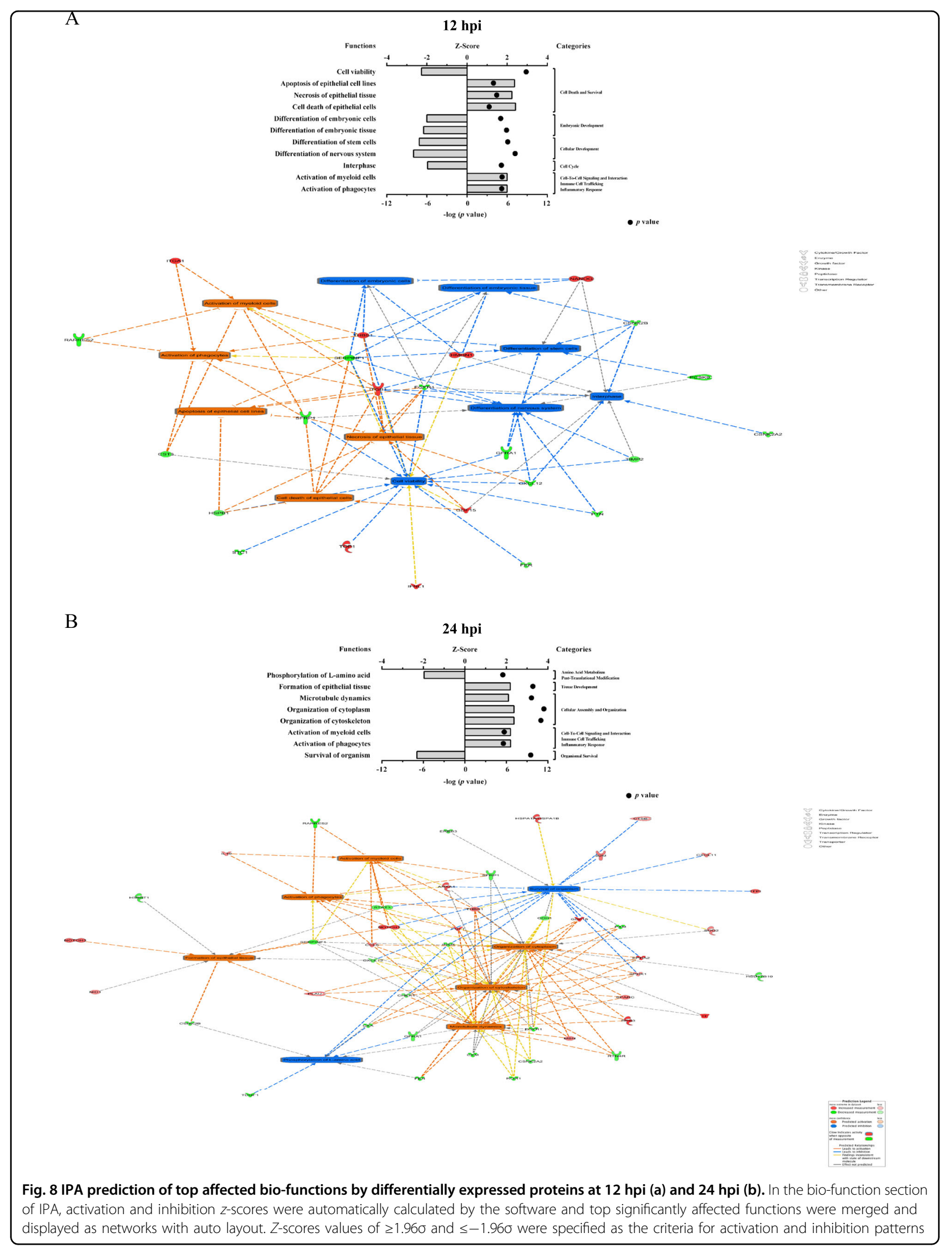


strain, was amplified in MDCK cells by infecting at MOI of 0.01 for $48 \mathrm{~h}$ and concentrated at $64,000 \times g$ for $2 \mathrm{~h}$ at $4{ }^{\circ} \mathrm{C}$. The virus was then titered by the plaque assay on MDCK cells.

\section{Infection and plaque assay}

After washing semiconfluent hiPSC colonies $2 \times$ with $1 \times$ phosphate buffered saline (PBS; $137 \mathrm{mM} \mathrm{NaCl}, 0.3 \mathrm{mM}$

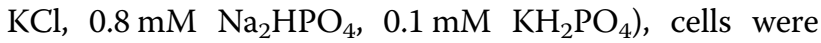
infected with PR8 virus diluted in E8 medium to achieve different MOIs, including 0.1, 1 , and 5 plaque forming units (PFU)/cell. To compare IAV growth kinetics in hiPSCs with other influenza-permissive cell lines, A549 and MDCK cells also were infected at the same MOIs by diluting the PR8 virus in gel saline $(137 \mathrm{mM} \mathrm{NaCl}$, $0.2 \mathrm{mM} \mathrm{CaCl} 2,0.8 \mathrm{mM} \mathrm{MgCl} 2,19 \mathrm{mM}$ HBO3, $0.1 \mathrm{mM}$ $\mathrm{Na} 2 \mathrm{~B} 4 \mathrm{O} 7,0.3 \%(\mathrm{w} / \mathrm{v})$ gelatin). An equivalent number of cells were mock-infected using either only E8 medium for PSCs or gel saline for other cells. At 12 and $24 \mathrm{hpi}$, infected and mock-infected hiPS and A549 cells were harvested for immunoblotting. To quantify the virus yield by the plaque assay, supernatants were collected from all three cell types at assigned time points and serially diluted 1:10 in gel saline. Diluted supernatants then were added to subconfluent monolayers of MDCK cells plated in sixwell dishes. Following an hour adsorption, cells were overlaid with $0.8 \%$ Avicel in FBS-free $1 \times$ DMEM media containing $2 \mathrm{mM}$ L-glutamine, $2 \mathrm{mM}$ sodium pyruvate, and $1 \times$ MEM nonessential amino acids, and supplemented with $2.5 \mu \mathrm{g} / \mathrm{mL}$ trypsin, $1 \times$ gentamicin and $1 \times$ amphotericin B. After $72 \mathrm{~h}$ incubation at $35^{\circ} \mathrm{C}$ to permit plaque formation, cells were fixed with $2 \%$ formaldehyde for $30 \mathrm{~min}$ and then stained with crystal violet for $1 \mathrm{~h}$. Viral titer was calculated as $\mathrm{PFU} / \mathrm{mL}$ by counting plaques $4 \mathrm{~h}$ after washing stained cell monolayers ${ }^{58}$.

\section{Immunoblotting}

At time points 12 and 24 hpi, mock- and influenzainfected hiPS and A549 cells were scraped into cold PBS, then pelleted at $500 \times g$ for $6 \mathrm{~min}$, and lysed for $15 \mathrm{~min}$ in mammalian protein extraction reagent $\left(\mathrm{M}-\mathrm{PER}^{\mathrm{TM}}\right.$, Thermo Scientific) supplemented with $\mathrm{HALT}^{\mathrm{TM}}$ protease inhibitor (Thermo Scientific). After clearing cell lysates by centrifugation at $14,000 \times g$ for $15 \mathrm{~min}$, supernatant protein contents were collected, and the BCA Protein Assay Kit (Pierce, Thermo Scientific) was applied to measure protein concentrations. Equal amounts of proteins were loaded per lane into SDS-polyacrylamide gels (SDSPAGE), fractionated, and transferred to Immobilon-P polyvinylidene difluoride membranes (Millipore). Membranes were blocked with $5 \%$ skim milk in Tris-Buffered Saline buffer containing $0.1 \%$ Tween 20 for $2 \mathrm{~h}$, and then incubated overnight with the desired primary antibodies at $4{ }^{\circ} \mathrm{C}$. Influenza primary anti-NP, $-\mathrm{M} 1$, and -NS1 antibodies were developed in-hous ${ }^{59}$. Primary antibodies for caspases-3, -7, -9, P53, Nanog, Sox2, Oct-4A, Bax, Bcl2, PSMA2, STAT3, SPARC, GAPDH, p62, and $\beta$-actin were purchased from Cell Signaling Technology. The LC3 $\beta$ and Atg 5 antibodies were obtained from Invi$\operatorname{trogen}^{\mathrm{TM}}$ and anti-Transferrin antibody was purchased from Abcam. Following overnight incubation with primary antibodies, membranes were probed with either rabbit or mouse HRP-conjugated secondary antibody (Cell Signaling) for $1 \mathrm{~h}$ at room temperature, and the bands were visualized through enhanced chemiluminescence detection machine (Amersham-Pharmacia Biotech). ImageJ software was used to quantify virus-to-mock ratios from the intensity of visualized bands. Blot quality was optimized for contrast and brightness using image settings plugin of Microsoft Word.

\section{Analysis of cellular morphology}

To examine PR8-induced CPE development, infected and mock-infected hiPSCs were assessed by inverted microscopy (Nikon TE-2000) at intended MOIs and photographed using a Canon A700 camera. The analysis of stem cell colony mass and size was done through crystal violet staining in a 12-well plate. After washing three times with PBS, hiPSCs were fixed with $4 \%$ paraformaldehyde for $15 \mathrm{~min}$ and then stained with $0.5 \%$ crystal violet solution in $4 \%$ paraformaldehyde for $10 \mathrm{~min}$. The stained plate was washed twice with water, and infected colonies were evaluated and compared to mockinfected wells on the next day.

\section{Assessment of cell viability}

The trypan blue exclusion assay was used to determine cell viability. Briefly, PR8-infected or mock-infected hiPSCs were harvested at various postinfection time points by brief trypsinization to break up the colonies. Single cells derived from disaggregated colonies then were washed, stained with trypan blue solution and placed on a hemocytometer for counting. The percentage of viable cells was calculated based on the number of dead (blue) cells divided by the total number of cells counted, multiplied by 100. The cytotoxicity of autophagy drugs (Rapamycin and Bafilomycin) was determined by the WST-1 cell proliferation assay (Roche, Germany) according to the manufacturer's instructions. In brief, hiPSCs or A549s grown in 96-well plates were treated with WST-1 reagent for $90 \mathrm{~min}$ at $37^{\circ} \mathrm{C}$. Colorimetric changes were measured, and cell viability then was calculated compared with controls.

\section{Indirect IF microscopy}

For IF staining, iPSCs were grown to $60 \%$ confluence on chamber slides and then infected or mock-infected with the PR8 virus at $\mathrm{MOI}=5$. After fixing with $4 \%$ 
paraformaldehyde for $15 \mathrm{~min}$ at 12 and $24 \mathrm{hpi}$, cells were permeabilized with $0.1 \%$ Triton X-100 in PBS for $5 \mathrm{~min}$ and blocked with 3\% BSA blocking solution for $90 \mathrm{~min}$. Afterward, cells were incubated overnight $4{ }^{\circ} \mathrm{C}$ with primary anti-Nanog, -Sox2, -Oct-4A (all three from Cell Signaling), -NS1, -NP, and -M1 (all three made in-house) antibodies diluted in 1\% BSA and PBS. After overnight incubation, cells were washed $5 \times$ with PBT buffer (PBS with $0.2 \%$ Tween-20) and treated for $1 \mathrm{~h}$ with Alexa Fluor $^{\text {rm }} 488$ and 546 (Invitrogen) secondary antibodies. Slides were then mounted using DAPI-Prolong ${ }^{\oplus}$ Gold Antifade for nuclear staining, sealed and preserved at $4{ }^{\circ} \mathrm{C}$ for imaging on the following day. Fluorescent images were acquired at $20 \times$ and $40 \times$ objective by Zeiss Axio Observer $\mathrm{Z} 1$ inverted microscope and further optimized with AxioVision 4.8.2 software. ImageJ software was used to quantify the levels of florescence signal intensities.

\section{Inhibition and activation of autophagy}

To establish a relationship between autophagy induction and loss of pluripotency, autophagic activity was blocked using autophagy inhibitor Bafilomycin A1 (Cayman Chemical), which inhibits autophagy through both hindering vacuolar acidification required for autophagosome maturation and mTOR activation ${ }^{60,61}$. Rapamycin (Sigma-Aldrich), an mTOR inhibitor and autophagy inducer $^{62}$, was utilized for elevating the level of autophagy. Both drugs were used in four different concentrations of $4000,500,50$, and $5 \mathrm{nM}$ for cytotoxicity analyses. Based on cell viability results, lower concentrations were selected for evaluating viral growth, autophagy, and pluripotency. In influenza-infected conditions, cells were first adsorbed with the virus at MOI of 5.0 for $1 \mathrm{~h}$ and then treated with selected concentration of Bafilomycin $(5 \mathrm{nM})$ or Rapamycin $(50 \mathrm{nM})$ mixed in cell-specific culture medium.

\section{SOMAscan screening}

After measuring protein concentrations in three biological replicates by the BCA assay, cell lysates were adjusted to $200 \mu \mathrm{g} / \mathrm{ml}$ and sent for proteomic screening using an in-house SOMAscan assay platform (version 1.3), a novel multiplexed system that uses modified nucleotides with high affinity known as SOMAmers (Slow Off-rate Modified Aptamers) to evaluate changes in the expression of intracellular proteins related to various biological processes $^{63}$. In total, the expressions of 1307 proteins were determined from lysates isolated at 12 and $24 \mathrm{hpi}$ from mock-infected and infected hiPSCs at MOI of 5 . Raw specific protein abundance values were obtained as relative fluorescence units (RFU). To sort out modified proteins, we calculated $z$-scores separately for each biological replicate to normalize all screened proteins at a $95 \%$ confidence level cutoff. $Z$-scores values of $\geq 1.96 \sigma$ and $\leq-1.96 \sigma$ were specified as the criteria for up- and downregulation patterns.

\section{Statistical and bioinformatic analysis}

Data were collected in triplicate from all experiments. For growth curves, cell viability, and band intensity analyses, statistical differences were assessed by one-way or two-way ANOVA, graphed using Graph Pad Prism 6.0, and results were reported as means \pm SDE. $P$-values $<0.05$ were considered statistically significant. To analyze SOMAscan results, RFU raw expression values were imported into Microsoft Excel and converted to $\log _{2}$ for calculating fold changes. $P$-values were determined using the two-tailed Student's t-test. To compare various biological replicates, $z$-scores were calculated from protein ratios within each replicate, as previously described ${ }^{58,63}$. Briefly, all fold changes not deemed to be significant by $t$ test were examined by $z$-score, expressing each value as its number of standard deviations away from the population mean. Protein IDs from the whole examined proteome were uploaded to and analyzed by IPA software. Panther databases were utilized to classify all significantly expressed proteins in gene ontology categories. Venn diagrams and heatmap were plotted using InteractiVenn and MORPHEUS (developed by Broad Institute, Cambridge, MA, USA) free online software, respectively.

\section{Acknowledgements \\ This research was supported by the Canadian Institutes of Health Research, by operating grant no. MOP-106713 to KMC and operating grant no. MOP-142265 to SD. The authors thank Protiti Khan for maintenance of stock cells, Ang Gao for SOMAscan analyses, Vic Spicer for statistical support and members of their laboratory group for helpful suggestions. G. L. S. was the recipient of a PhD Fellowship from Research Manitoba, and A. Z-A. was the recipient of a Graduate Enhancement Training Studentship and of an Allen Ronald Studentship from the University of Manitoba.}

\section{Author details}

'Department of Medical Microbiology and Infectious Diseases, University of Manitoba, Winnipeg, MB, Canada. ${ }^{2}$ Manitoba Centre for Proteomics and Systems Biology, Winnipeg, MB, Canada. ${ }^{3}$ Department of Physiology and Pathophysiology, University of Manitoba, Winnipeg, MB, Canada. ${ }^{4}$ Institute of Cardiovascular Sciences, Albrechtsen Research Centre, St. Boniface Hospital, Winnipeg, MB, Canada. ${ }^{5}$ Children's Hospital Research Institute of Manitoba, Winnipeg, MB, Canada

\section{Author contributions}

A.Z.-A. performed most experiments, interpreted the results and wrote the manuscript first draft. G.L.S. prepared the hiPS cells for experimental use and edited the manuscript. S.D. and K.M.C. provided overall guidance, interpreted the results and edited the manuscript.

Conflict of interest

The authors declare that they have no conflict of interest.

\section{Publisher's note}

Springer Nature remains neutral with regard to jurisdictional claims in published maps and institutional affiliations.

Supplementary Information accompanies this paper at (https://doi.org/ 10.1038/s41419-019-1567-4). 
Received: 1 October 2018 Revised: 26 March 2019 Accepted: 4 April 2019 Published online: 18 April 2019

\section{References}

1. Engels, G. et al. Pregnancy-related immune adaptation promotes the emergence of highly virulent H1N1 influenza virus strains in allogenically pregnant mice. Cell Host Microbe 21, 321-333 (2017).

2. Rasmussen, S. A., Jamieson, D. J. \& Uyeki, T. M. Effects of influenza on pregnant women and infants. Am. J. Obstet. Gynecol. 207, S3-S8 (2012).

3. Luteijn, J. M., Brown, M. J. \& Dolk, H. Influenza and congenital anomalies: a systematic review and meta-analysis. Hum. Reprod. 29, 809-823 (2013).

4. Leck, I., Hay, S., Witte, J. J. \& Greene, J. C. Malformations recorded on birth certificates following A2 influenza epidemics. Public Health Rep. 84, 971-979 (1969).

5. Coffey, V. P. \& Jessop, W. J. E. Maternal influenza and congenital deformities. A follow-up study. Lancet 281, 748-751 (1963).

6. Czeizel, A. E., Puhó, E. H., Ács, N. \& Bánhidy, F. Use of specified critical periods of different congenital abnormalities instead of the first trimester concept. Birth Defects Res. Part A: Clin. Mol. Teratol. 82, 139-146 (2008).

7. $\mathrm{Gu}$, J. et al. H5N1 infection of the respiratory tract and beyond: a molecular pathology study. Lancet 370, 1137-1145 (2007).

8. Yawn, D. H., Pyeatte, J. C., Joseph, J. M., Eichler, S. L. \& Garcia-Bunuel, R. Transplacental transfer of influenza virus. J. Am. Med. Assoc. 216, 1022-1023 (1971).

9. Lieberman, R. W., Bagdasarian, N., Thomas, D. \& Van De Ven, C. Seasonal influenza $A(\mathrm{H} 1 \mathrm{~N} 1)$ infection in early pregnancy and second trimester fetal demise. Emerg. Infect. Dis. 17, 107-110 (2011).

10. Jewett, J. F. Influenza pneumonia at term. N. Engl. J. Med. 291, 256-257 (1974).

11. Khatri, M. \& Chattha, K. S. Replication of influenza A virus in swine umbilical cord epithelial stem-like cells. Virulence 6, 40-49 (2015).

12. Khatri, M., Goyal, S. M. \& Saif, Y. M. Oct4+ stem/progenitor swine lung epithelial cells are targets for influenza virus replication. J. Virol. 86, 6427-6433 (2012).

13. Pringproa, K. et al. Tropism and induction of cytokines in human embryonicstem cells-derived neural progenitors upon inoculation with highlypathogenic avian H5N1 influenza virus. PloS One 10, e0135850 (2015).

14. Wash, R. et al. Permissive and restricted virus infection of murine embryonic stem cells. J. Gen. Virol. 93, 2118-2130 (2012).

15. Shapira, S. D. et al. A physical and regulatory map of host-influenza interactions reveals pathways in H1N1 infection. Cell 139, 1255-1267 (2009).

16. Kash, J. C., Goodman, A. G., Korth, M. J. \& Katze, M. G. Hijacking of the host-cell response and translational control during influenza virus infection. Virus Res. 119, 111-120 (2006)

17. Gannagé, M. et al. Matrix protein 2 of influenza A virus blocks autophagosome fusion with lysosomes. Cell Host Microbe 6, 367-380 (2009).

18. Ludwig, S., Pleschka, S., Planz, O. \& Wolff, T. Ringing the alarm bells: signalling and apoptosis in influenza virus infected cells. Cell Microbiol. 8, 375-386 (2006).

19. Sumbayev, V. V. \& Yasinska, I. M. Role of MAP kinase-dependent apoptotic pathway in innate immune responses and viral infection. Scand. J. Immunol 63, 391-400 (2006).

20. Hale, B. G., Randall, R. E., Ortín, J. \& Jackson, D. The multifunctional NS1 protein of influenza A viruses. J. Gen. Virol. 89, 2359-2376 (2008).

21. Rahim, M., Klewes, L., Zahedi-Amiri, A., Mai, S. \& Coombs, K. Global interactomics connect nuclear mitotic apparatus protein NUMA1 to influenza virus maturation. Viruses 10, 731 (2018).

22. Hossini, A. M. et al. PI3K AKT signaling pathway is essential for survival of induced pluripotent stem cells. PloS One 11, e0154770 (2016).

23. Hübner, D. et al. Infection of iPSC lines with miscarriage-associated coxsackievirus and measles virus and teratogenic rubella virus as a model for viral impairment of early human embryogenesis. ACS Infect. Dis. 3, 886-897 (2017).

24. Smith-Arica, J. R. et al. Infection efficiency of human and mouse embryonic stem cells using adenoviral and adeno-associated viral vectors. Cloning Stem Cells 5, 51-62 (2003).

25. Wagner, R., Wolff, T., Herwig, A., Pleschka, S. \& Klenk, H. D. Interdependence of hemagglutinin glycosylation and neuraminidase as regulators of influenza virus growth: a study by reverse genetics. J. Virol. 74, 6316-6323 (2000).

26. Satomaa, T. et al. The N-glycome of human embryonic stem cells. BMC Cell Biol. 10, 42 (2009)

27. Atwood lii, J. A. et al. Quantitation by isobaric labeling: applications to glycomics. J. Proteome Res. 7, 367-374 (2007).
28. Wang, R. et al. Mouse Embryonic stem cells (mESCs) are deficient in type I interferon expression in response to viral infections and double-stranded RNA (dsRNA). J. Biol. Chem. 288, 15926-15936 (2013).

29. Reibetanz, U., Hübner, D., Jung, M., Liebert, U. G. \& Claus, C. Influence of growth characteristics of induced pluripotent stem cells on their uptake efficiency for layer-by-layer microcarriers. ACS Nano 10, 6563-66573 (2016).

30. Wang, R. et al. Antiviral responses in mouse embryonic stem cells: differential development of cellular mechanisms in type I interferon production and response. J. Biol. Chem. 289, 25186-25198 (2014).

31. Levine, B., Sinha, S. C. \& Kroemer, G. Bcl-2 family members: dual regulators of apoptosis and autophagy. Autophagy 4, 600-606 (2008).

32. Ouyang, L. et al. Programmed cell death pathways in cancer: a review of apoptosis, autophagy and programmed necrosis. Cell Prolif. 45, 487-498 (2012).

33. Chen, W. et al. A novel influenza A virus mitochondrial protein that induces cell death. Nat. Med. 7, 1306-1312 (2001).

34. Zhirnov, O. P., Konakova, T. E., Wolff, T. \& Klenk, H. D. NS1 protein of influenza A virus down-regulates apoptosis. J. Virol. 76, 1617-1625 (2002).

35. Ehrhardt, C. et al. Influenza A virus NS1 protein activates the PI3K Akt pathway to mediate antiapoptotic signaling responses. J. Virol. 81, 3058-3067 (2007).

36. Yeganeh, B. et al. Autophagy activation is required for influenza A virusinduced apoptosis and replication. Biochim. Biophys. Acta Mol. Cell Res. 1865 364-378 (2018).

37. Mizushima, N. Autophagy: process and function. Genes Dev. 21, 2861-2873 (2007).

38. Yoshimura, A. \& Ohnishi, S. Uncoating of influenza virus in endosomes. J. Virol. 51, 497-504 (1984).

39. Bui, M., Whittaker, G. \& Helenius, A. Effect of M1 protein and low $\mathrm{pH}$ on nuclear transport of influenza virus ribonucleoproteins. J. Virol. 70, 8391-8401 (1996).

40. Zhou, Z. et al. Autophagy is involved in influenza A virus replication. Autophagy 5, 321-328 (2009).

41. Comber, J. D., Robinson, T. M., Siciliano, N. A., Snook, A. E. \& Eisenlohr, L. C. Functional macroautophagy induction by influenza A virus without a contribution to MHC-class II restricted presentation. J. Virol. 85, 6453-6463 (2011).

42. Kroemer, G. \& Levine, B. Autophagic cell death: the story of a misnomer. Nat Rev. Mol. Cell Biol. 9, 1004-1010 (2008).

43. Tsukamoto, S. et al. Autophagy is essential for preimplantation development of mouse embryos. Science 321, 117-120 (2008).

44. Guan, J. L. et al. Autophagy in stem cells. Autophagy 9, 830-849 (2013).

45. Mizushima, N. \& Levine, B. Autophagy in mammalian development and differentiation. Nat. Cell Biol. 12, 823-830 (2010).

46. Qu, X. et al. Autophagy gene-dependent clearance of apoptotic cells during embryonic development. Cell 128, 931-946 (2007).

47. Vilchez, D. et al. Increased proteasome activity in human embryonic stem cells is regulated by PSMD11. Nature 489, 304-308 (2012).

48. Tra, T. et al. Autophagy in human embryonic stem cells. PloS One 6, e27485 (2011).

49. Wullschleger, S., Loewith, R. \& Hall, M. N. TOR signaling in growth and metabolism. Cell 124, 471-484 (2006).

50. Hay, N. \& Sonenberg, N. Upstream and downstream of mTOR. Genes Dev. 18 1926-1945 (2004)

51. Zhou, J. et al. mTOR supports long-term self-renewal and suppresses mesoderm and endoderm activities of human embryonic stem cells. Proc. Natl Acad. Sci. 106, 7840-7845 (2009).

52. Fathi, A. et al. Comprehensive gene expression analysis of human embryonic stem cells during differentiation into neural cells. PloS One 6, e22856 (2011).

53. Guo, Y. L. Utilization of different anti-viral mechanisms by mammalian embryonic stem cells and differentiated cells. Immunol. Cell Biol. 95, 17-23 (2017).

54. Földes, G. et al. Innate immunity in human embryonic stem cells: comparison with adult human endothelial cells. PLoS One 5, e10501 (2010).

55. Yu, J., Rossi, R., Hale, C., Goulding, D. \& Dougan, G. Interaction of enteric bacterial pathogens with murine embryonic stem cells. Infect. Immun. 77, 585-597 (2009)

56. Szutorisz, H., Georgiou, A., Tora, L. \& Dillon, N. The proteasome restricts permissive transcription at tissue-specific gene loci in embryonic stem cells. Cell 127, 1375-1388 (2006).

57. Sequiera, G. et al. Establishment of stable in vitro cardiac models of KearnsSayre syndrome using induced pluripotent stem cell technology. Can. J. Cardiol. 33, S166 (2017). 
58. Coombs, K. M. et al. Quantitative proteomic analyses of influenza virusinfected cultured human lung cells. J. Virol. 84, 10888-10906 (2010).

59. Rahim, M. N. et al. Generation and characterization of a new panel of broadly reactive anti-NS1 mAbs for detection of influenza A virus. J. Gen. Virol. 94 593-605 (2013).

60. Yamamoto, A. et al. Bafilomycin A1 prevents maturation of autophagic vacuoles by inhibiting fusion between autophagosomes and lysosomes in rat hepatoma cell line, H-4-I-E cells. Cell Struct. Funct. 23, 33-42 (1998).
61. Shacka, J. J., Klocke, B. J. \& Roth, K. A. Autophagy, bafilomycin and cell death: the "a-B-cs" of plecomacrolide-induced neuroprotection. Autophagy $\mathbf{2}$, 228-230 (2006)

62. Jung, C. H., Ro, S. H., Cao, J., Otto, N. M. \& Kim, D. H. mTOR regulation of autophagy. FEBS lett. 584, 1287-1295 (2010).

63. Glover, K. K., Gao, A., Zahedi-Amiri, A. \& Coombs, K. M. Vero cell proteomic changes induced by Zika virus infection. Proteomics 19, e1800309 (2018). 